\title{
From the Museum: the Art of Thinking
}

\author{
Tom Kotsimbos
}

Affiliations: Dept of Medicine, Central Clinical School, Monash University, Melbourne, Victoria and Dept Allergy, Immunology and Respiratory Medicine, Alfred Hospital, Melbourne, Victoria, Australia.

Correspondence: T. Kotsimbos, Dept of Medicine, Central Clinical School, Monash University; Dept Allergy, Immunology and Respiratory Medicine, Alfred Hospital, Melbourne, Victoria, 3004, Australia.

E-mail: tom.kotsimbosamonash.edu

It is the mark of an educated mind to be able to entertain a thought without accepting it

- Aristotle

Art is a lie that enables us to realise the truth

- Picasso

It is with great pleasure and a sense of adventure that we introduce a new feature in this month's European Respiratory Journal [1] focusing on the creative arts as essential complements to the scientific method in the never-ending quest of knowing our world.

The primary purpose of this series over the next 12 months will be to use key pieces of revolutionary European art spanning the last 500 years to anchor "musings" on the "Art of Thinking" and spark crossdisciplinary conversations, insights and extrapolations between the Arts, Science and Philosophy.

From the outset, our challenge is to elevate your "thinking about thinking" and to creatively engage with new thought as it both defined and was derivative of the human mind during key periods of European artistic and scientific development commencing with Renaissance awakenings, through the passions of the Romantic age, Enlightenment's revelations and the powers of Symbolism, culminating in Modern art's abstractions. The specific artworks selected for this series can be considered revolutionary at their core due to their association with different ways of thinking. Analogous to a museum visit, we then challenge you, the viewer/reader, to look at famous art from different perspectives depending on how it has been contextualised and exhibited. In each case, art reflects on art while being framed by the language and patterns of science juxtaposed with relevant thinking (deconstructed and reconstructed using explanatory language) and set within a specific period of historical change as it related to the broader contemporary humanities, science and technology. The viewer, whether they be clinician, scientist or creative artist most broadly defined, is then invited to examine their response to what has been presented and let their mind wander to other areas of human endeavour in which they may be well positioned to combine generalist extrapolations with specialist insights.

While some may think it ambitious to use a specialist medical journal to frame such a series, it is perhaps a sign of the increasing confidence of the ERJ under its current leadership to creatively break new ground as part of a multi-faceted strategy of growth and renewal designed to maintain relevance, connectivity and value in a world where there are increasing islands of super-specialisation. The success of science and medicine over the past 50 years in looking deeper and deeper into our biology and in intervening more and more in that biology has led to an explosion in the number of high-quality journals even within any given sub-specialty. With this success, however, comes the need to rethink the old knowledge and debate the new,

@ERSpublications

From the Museum: a new ERJ series exploring the art of thinking

http://ow.ly/ssiAU

Received: Jan 022014 | Accepted: Jan 092014

Conflict of interest: None declared.

Copyright @ERS 2014 
to incorporate novel ways of looking and understanding, and to express new information in all its unifying power for maximal impact. In this way, the dynamics between specialist knowledge and general application parallel the Aristotelean model of thesis clashing with antithesis to constantly drive each other towards a newer and more meaningful synthesis. This process is at the core of value creation and arguably should be the defining principle of our age.

What is true within the sciences is also true between science and the arts. By both framing art in a scientific journal and using art to frame scientific thinking, it is possible to start playing with the idea of art and science supporting each other across multiple dimensions. From this platform we can make a quantum leap into an exploration of how humanity's two grandest processes of knowing provide a counterpoint to each other: intellectual versus intuitive, reductionism versus synthesis, and analytic versus holistic. The constant tension that results from these opposing world-views is at its worst a destructive power struggle and at its best an ever-present source of renewal, novel ideation and creativity.

How do we keep the best that the "old ways of knowing" and the benefits of generalisation have to offer and combine it with "new ways of knowing" and the power of specialisation? One way to unleash our thinking is to combine the resonating power of an algorithmic approach with the magic of images, juxtaposition and a framing metaphor and to apply this to the example of revolutionary art to explore key aspects of thinking, looking and doing that were fundamental to the revolution they describe. More specifically, an examination of revolutionary European artists and their art within a broader humanistic-scientific context that is itself creatively composed within a relevant exploration of avant-garde thinking (philosophically deconstructed and appropriately reimagined) is an extremely liberating force for original insights and innovative extrapolations. After all, categorisation and analogy-making are at the core of creative thinking. Novel imaginings, connections and understanding can then directly flow from such an intimate intertwining of cause and effect within each piece and temporally across the series. Each of the 12 creations therefore stands alone as a statement regarding the "art of thinking" within which the arts, sciences and philosophy all metaphorically frame each other; and is part of a broader project narrative that gradually reveals itself such that the series as a whole is much greater than the sum of its individual parts.

The practice of medicine has always sat deliciously between the humanities and the sciences, and so our musings on the art of thinking have immediate and direct relevance. However, more subtly and more than ever before, we need to continually embrace the value of clinical medicine's unique position - dynamically set between the rigour of scientific method and the necessity of humanistic approaches - along with all the quanta of uncertainty that this entails and the tolerance required to manage it, as a guiding beacon for how to best think about the science of health and the art of caring for the human condition in a rapidly changing and increasingly connected world.

\section{References}

1 Kotsimbos T. From the Museum: the Art of Thinking. Part One: Thinking. Eur Respir J 2014; 43: 702-703. 